\title{
O filme como pretexto para estudar o Brasil do Espelho D'Água
}

Maria Ignês Carlos Magno

Doutora em Ciências da Comunicação pela ECA/USP.

Professora do curso de Pedagogia do Centro Universitário Salesiano

de São Paulo e da Universidade Anhembi Morumbi.

E-mail: unsig@globo.com

Dorme o sol à flor do Chico, meio-dia tudo esbarra embriagado de seu lume dorme ponte, Pernambuco, Rio, Bahia só vigia um ponto negro o meu ciúme

o ciúme lançou sua flecha preta

e se viu ferido justo na garganta

que nem alegre nem triste nem poeta entre Petrolina e Juazeiro canta velho Chico vens de Minas de onde o oculto do mistério se escondeu sei que o levas em ti não me ensinas e eu sou só eu sou só eu

Juazeiro, nem te lembras desta tarde

Petrolina nem chegaste a perceber mas, na voz que canta tudo ainda arde tudo é perda, tudo quer buscar cadê tanta gente canta tanta gente cala tantas almas esticadas no curtume

sobre toda estrada, sobre toda sala paira, monstruosa, a sombra do ciúme

(Caetano Veloso. O Ciúme ${ }^{1}$ )

Entre setembro e outubro de 2005, o Brasil e outras regiões do mundo foram surpreendidos por um ato aparentemente fora de contexto: dom Luiz Flavio Cappio, bispo diocesano de Barra (BA), estava em greve de fome e o motivo era o Rio São Francisco. Quem era dom Luiz e por que a greve de fome em defesa de um rio? Para o Brasil, um paulista de Guaratinguetá, formado em teologia, filosofia e economia. Para a população ribeirinha, é dom Luiz, o franciscano que chegou ao semi-árido do Nordeste em 1974 e nunca mais deixou de lutar pelo rio e pela população que vive às margens do São Francisco.

1. CAETANO VELOSO.

$\mathrm{O}$ ciúme. Rio de Janeiro: Polygram, 1987. 1 CD. 
Apesar de seus 32 anos de luta, frei Luiz ficou conhecido após a peregrinação que fez pelo rio São Francisco entre 1992 e 1993, quando chamou a atenção das autoridades para a situação de degradação do rio. Atualmente, diz que sua "batalha é mostrar, para o governo e para o povo, a necessidade de levar a sério o projeto de revitalização do São Francisco"”.

Nos onze dias de greve, frei Luiz obrigou políticos, pesquisadores e a população brasileira em geral a tomar conhecimento e a pensar nos dois projetos governamentais para o rio e regiões que atravessa: a transposição e a revitalização do São Francisco. Cantado em rezas, homenageado em letras de músicas e nas artes em geral, o rio São Francisco, que nas palavras do frei Luiz: "há muito deixou de ser um acidente geográfico e passou a ser a condição de vida para todo o povo da região" , merece um estudo mais aprofundado.

Considerando o quase um ano do acontecido, o silêncio dos órgãos públicos e da mídia em geral sobre o andamento dos projetos, o filme de Marcus Vinícius Cezar pode ser um pretexto para conhecermos o Brasil do Espelho D'Água e continuarmos a discussão que, mesmo não estando agendada pelos meios de comunicação, pode e deve fazer parte de nossas inquietações e debates. Pensando em tudo que as imagens e os textos nos dão a conhecer e nos incitam a desvendar, pensei em propor para essa Videografia um estudo da geopolítica e da cultura brasileiras.

\section{FICHA TÉCNICA}

\section{Espelho D’Água - Uma Viagem no Rio São Francisco}

Direção - Marcus Vinícius Cezar

Roteiro - Marcus Vinícius Cezar, Lara Francischetti e Yoja Wursh

Música - Naná Vasconcelos

Fotografia - José Tadeu Ribeiro

Direção de arte - Oscar Ramos

Edição - Tuco

Gênero - Drama

Ano - 2004

2. Disponivel em: <http:// carosamigos.terra.com. $\mathrm{br/do \_ site/sonosite/}$ entrev_mar06_freicappio. asp $>$.

3. <www.umavidapelavida. com.br>.
O filme de Marcus Vinícius Cezar, lançado em 2004 após quatro anos de pesquisas e oito semanas de gravações, recebeu dois prêmios no Festival do Audiovisual de Pernambuco e o troféu Margarida de Prata conferido pela CNBB. Rodado nas cidades de Penedo em Alagoas, Juazeiro na Bahia e Petrolina em

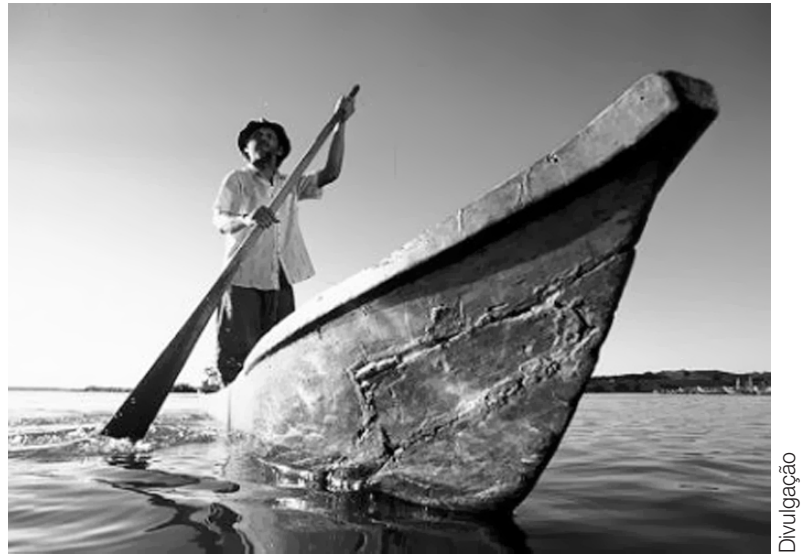




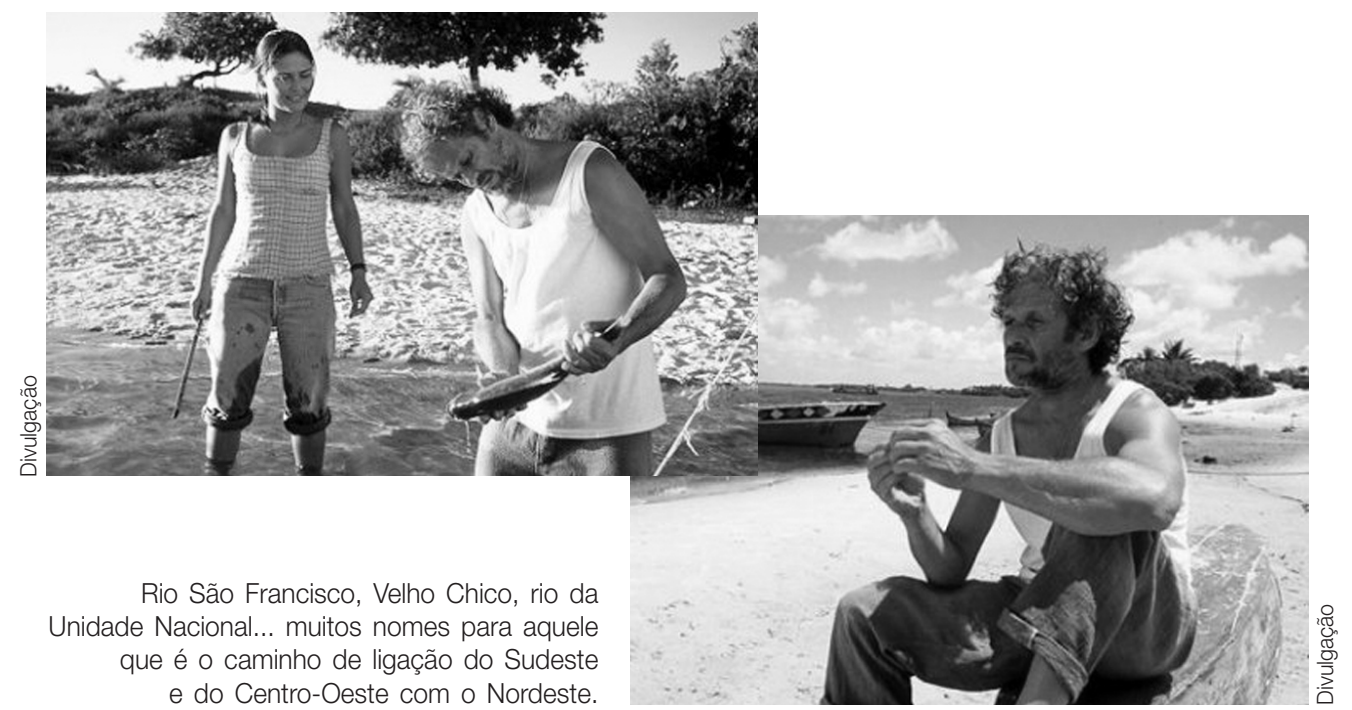

Pernambuco, conta a história de Henrique, um fotógrafo em crise que decide viajar pelo rio São Francisco.

O vale do rio São Francisco é um universo à parte, que apresenta uma vida simples e rica, com suas lendas e seus mistérios. Celeste, uma jovem carioca, vai para o São Francisco para encontrar o fotógrafo Henrique, seu namorado. Ao chegar à cidade de Penedo, fica sabendo que Henrique saiu de barco pelo rio para fotografá-lo. Ela decide percorrer o rio a sua procura e descobre o mundo dos ribeirinhos. Durante a viagem Henrique também conhece várias lendas sobre o rio e as pessoas que dele dependem para viver.

O filme, que contou com o patrocínio da Companhia de Desenvolvimento dos Vales do São Francisco e do Parnaíba - Codevasp, foi considerado um documentário disfarçado de fábula, e mostra, ainda que de forma leve, as lendas, as crenças, os costumes e mesmo os problemas de assoreamento e a ameaça de extinção de espécies de sua fauna. Dados que interessam na medida em que podem compor, além de pesquisas, parte das discussões sobre o vale e sobre o filme em si.

\section{UM RIO DE MUITAS HISTÓRIAS}

$\mathrm{O}$ rio São Francisco, mais conhecido como o velho Chico e o rio da unidade nacional, tem sua razão de ser. De acordo com a lenda, o São Francisco nasceu das lágrimas derramadas pela índia Irati, que, de tanto chorar pelo seu guerreiro que fora lutar pela posse da terra contra o homem branco e nunca mais voltou, fez nascer o Opará, que na língua indígena significa rio-mar. Geograficamente, o São Francisco nasce no Chapadão do Zagaia, na Serra da Canastra, atravessa os estados de Minas Gerais, Bahia, Sergipe, Pernambuco e Alagoas, percorre $2.700 \mathrm{~km}$ e deságua no mar do Nordeste. Ao longo do vale vivem aproximadamente 14 milhões de habitantes que foram, em seus cinco séculos de história, povoando as margens e o imaginário de todos que vivem e convivem com o velho Chico. 
4. COELHO, Marco Antonio T. Os descaminhos do São Francisco. Rio de Janeiro: Paz e Terra, 2005.

5. NOVAES, Washington. A transposição demolida antes de começar. Estudos Avançados, São Paulo, v. 20, n. 56, 2006. Disponível em: <http://www.scielo. $\mathrm{br} / \mathrm{scielo}$.php?script $=$ sci arttext\&pid=S0103-40142 $006000100023 \& \operatorname{lng}=p t \& n$ rm=iso $>$.
A posição geográfica do rio sempre foi vista como um privilégio para os colonizadores portugueses na ocupação das terras do interior. E, se num primeiro momento, o rio servia apenas de caminho natural entre o Sul e o Norte, após o domínio do litoral passou a ser a estrada que favorecia a colonização do sertão brasileiro. Nesse desbravar, o choro de Irati pelo primeiro confronto de posse da terra. Fora da ficção, o rio serviu de caminho para os colonizadores caçarem índios para o cativeiro e, em seguida, transformarem suas margens em imensos currais, pois, logo após a descoberta do ouro nas Gerais, o gado trazido de Cabo Verde alimentaria a massa que se deslocou para a região das minas.

País do São Francisco para alguns pesquisadores, civilização do São Francisco para outros, o importante é saber que essas nomeações resultam da própria história do rio, desde sua origem. Primeiro, a ligação com os princípios da colonização e o posterior isolamento, a partir do século XVIII, quando as autoridades portuguesas determinaram um novo caminho entre as minas de ouro e o Rio de Janeiro; em seguida, a Coroa resolveu transferir a sede do governo de Salvador para o Rio de Janeiro, em 1763, o que reduziu sua importância. De porta de entrada para o interior e para as regiões das minas de ouro, também foi "rota para os campos do Piauí e do Maranhão, assim como as bacias do Tocantins-Araguaia", nas palavras do pesquisador Marco Antonio T. Coelho. $\mathrm{Na}$ apresentação do livro de Coelho, Washington Novaes, jornalista, consultor ambiental e ex-secretário de Meio Ambiente, Ciências e Tecnologia de Brasília, ressalta o capítulo sobre a civilização do São Francisco:

[...] durante os trezentos anos de isolamento, de sua permanência à margem do capitalismo, a constituição até de uma linguagem peculiar, a economia quase só de subsistência. E três fatores foram fundamentais para o delineamento dessa civilização: a implantação do regime de sesmarias pela matriz lusitana - como modelo de ocupação do território e manutenção da soberania -, a pecuária extensiva e o coronelismo e o compadrio. Disso tudo resultou um modo de vida assentado em dois esteios - o regime de propriedade privada e o compadrio, os dois pilares da sociedade. Nesse quadro, o São Francisco viu nascer os maiores latifúndios do Brasil, a Casa da Torre (família Garcia d'Ávila) e a Casa da Ponte (família Guedes de Brito). Da união entre propriedade privada e família surge a fazenda como núcleo econômico e social, demográfico e cultural da civilização do São Francisco 5 .

Também vem das análises de Coelho a informação de que a navegação e o uso do rio têm sido alvos de interesse dos governantes desde D. Pedro II. Relata Coelho que o imperador, impressionado com o papel desempenhado na ocupação dos Estados Unidos pela navegação no rio Mississipi, encomendou estudos a vários técnicos sobre a possibilidade de valorizar esse meio de transporte no São Francisco. E a navegação teve, durante 250 anos, entre 1871 e 1950, uma grande importância.

Para termos uma idéia, especificamente sobre o rio das Velhas - o principal afluente do velho Chico - o qual desempenhou um papel especial nessa história, conta-se que

Henrique Dumont, pai de Alberto Santos Dumont, chegou a construir embarcações movidas a vapor. O navio a vapor, construído em 1869, fora batizado de 
Conselheiro Saldanha - na época, governador da Província; os navios transportavam pedras preciosas $^{6}$.

Depois de 1950, vieram as hidrelétricas de Três Marias, Sobradinho e Itaparica, além das várias etapas de Paulo Afonso e Xingó. Começaram a irrigação de lavouras, a implantação de fruticultura, o avanço da soja no oeste da Bahia e hoje, de acordo com os estudos de Marco Antonio T. Coelho, o panorama do São Francisco é o da disputa permanente em torno do uso das águas. De rio da unidade nacional, tornou-se o rio da disputa pela água entre regiões do Nordeste meridional e Nordeste setentrional.

De acordo com estudiosos, o vale do São Francisco já perdeu três dos 16 afluentes perenes. Os rios Verde Grande, Salitre e Ipanema se tornaram temporários, reduzindo o volume de água disponível para navegação, irrigação, pesca e geração de energia.

Os três rios deixaram de ser perenes por causa da ação das siderúrgicas de Minas Gerais e das mineradoras baianas - que utilizam a mata ciliar na produção de carvão -, além da poluição das metrópoles; por exemplo, Belo Horizonte, situada na bacia do São Francisco, castiga o rio das Velhas, com o lançamento de esgoto de uma população superior a 4 milhões de habitantes. "O rio São Francisco permanece descurado e está entregue à própria sorte. O abandono é nele todo", reclama José Theodomiro, presidente do Comitê Executivo de Estudos Integrados da Bacia Hidrográfica do São Francisco, respeitado como a maior autoridade nas questões do rio. Segundo o historiador Theodoro Souza, apenas para ilustrar a afirmação, desde 1906, a administração central pouco se interessou por uma melhor organização e assistência às populações sertanejas, excetuando-se o período das minas, e só houve "coibição de abusos e o amortecimento da ação dos poderes dos chefes regionais no curto período da mineração, porque eles embaraçavam de algum modo a máquina tributária"7.

Atualmente sabemos que seu leito está cada vez mais assoreado, poluído, com a atividade pesqueira diminuída e boa parte da população ribeirinha deixada à própria sorte; como também temos conhecimento de que o São Francisco vem sendo há muito destratado. No entanto, da mesma forma é propalada a resistência da população que, entre outros fatores, insiste em permanecer em seus lugares de origem, em razão de suas crenças, histórias e memórias construídas ao longo de seus cinco séculos de existência.

\section{ESPELHO D'ÁGUA - OUTRAS VIAGENS AO SÃO FRANCISCO}

A primeira imagem do filme é a do rio e uma canoa flutuando. São Francisco - santo da ecologia - é padroeiro de Opará/São Francisco. Sidó é o nome da canoa falante que servirá de mediação entre a ficção-fábulas e a ficção-realidades narradas pelo filme.

Ao recitar os nomes de todos os tipos de madeira que existiam no Brasil, Sidó se apresenta como a descendente de uma das mais nobres: o jatobá. Em suas memórias, o tempo corre depressa demais. Suas origens, iguais às do rio, foram sendo engolidas não só pelo tempo natural, mas pelo tempo de uma história em que os interesses econômicos se esqueceram do rio-mar e das pessoas que vivem às margens do vale e à margem dessa história.

6. Disponível em: <http:// www.agrisustentavel.com/ doc/francisco.htm>

7. Ibid. 
Penedo (AL) é onde o filme começa, e tem duas personagens principais: o São Francisco e a fotografia de José Tadeu Ribeiro. Henrique é o fotógrafo que na trama fará a viagem pelo rio e irá nos mostrar, além da boniteza do espelho d'água e da destruição que se esconde sob ele, aspectos da cultura-tradição que ainda resiste no encontro com a cultura-consumo, determinada pelos interesses da globalização. E o primeiro retrato dessa cultura são as mulheres lavadeiras do São Francisco e suas canções. Entre elas, Penha, amiga de Henrique e voz da cultura-tradição. Pela voz de Penha, conhecemos os cantos, as visões dos sonhos e seus significados, a mão-parteira e as rezas cantadas no momento do nascimento de uma criança. É ela também quem, ao entregar uma cabaça para que Henrique solte no São Francisco a fim de que chegue até Bom Jesus da Lapa, revela dois aspectos de uma mesma história: o assoreamento do Rio e a angústia de perder-se um de seus rituais mais antigos, o das cabaças iluminadas que correm pelo São Francisco até Bom Jesus da Lapa, local santo e milagreiro.

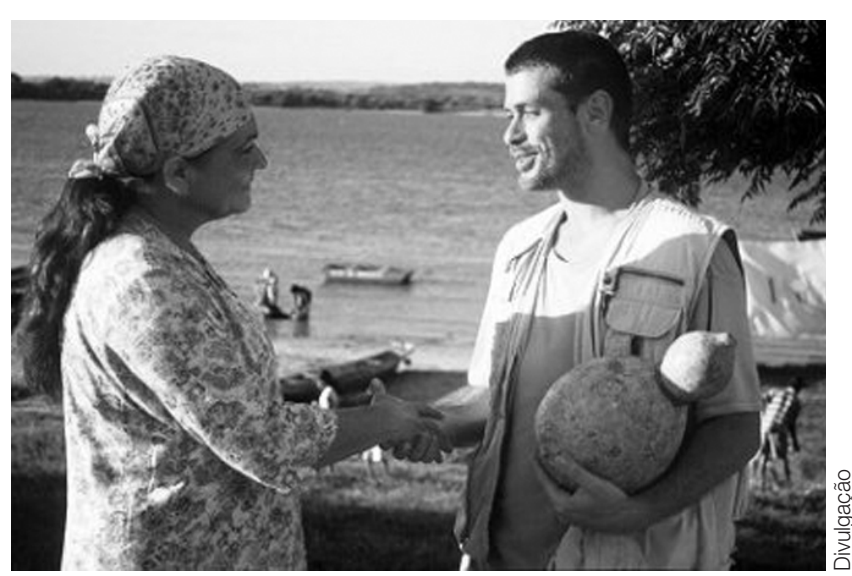

Num mundo globalizado e praticamente sem fronteiras, o vale do rio São Francisco é um universo à parte, uma vida simples e rica, permeada por tradições seculares que estão desaparecendo.

Outro personagem enredado na cultura-tradição é o remeiro Abel, quase uma simbiose com Sidó, sua canoa falante. Sua fala revela outras histórias do rio, da cultura ribeirinha e das relações dessa população com o São Francisco. Uma delas é a das entidades lendárias que povoam o imaginário das pessoas e dos lugares, como o Bicho d'Água, o Curupira, o Pé-de-Garrafa, o Minhocão. Dentre todos, destaca-se a força mítica do Bicho d'Água que habita as águas do São Francisco. Questionado sobre o fato de que ninguém o vê, Abel responde: "Deus também existe e nunca foi retratado". Em uma de suas visões, avista um antigo barco de remeiros navegando pelo São Francisco e ouve a voz de Sidó dizendo: "Lá é miração, né, meu véio". Miragens de uma profissão quase desaparecida.

Henrique parte para Petrolina no médio São Francisco para fazer fotos aéreas, sobrevoando o rio de helicóptero. Antes, tenta falar com Celeste, sua namorada, que vive no Rio de Janeiro. De um orelhão, fotografa uma seqüência em que Candelário, líder dos ribeirinhos, discursa sobre a morte escondida sob o espelho d'água. Na seqüência do filme revelado por Henrique, Candelário aparece em preto-e-branco e, ao fundo, o São Francisco, colorido, lindo, como seus olhos sempre tinham visto e fotografado. Sob a observação atenta de Abel, Henrique vai para o médio São Francisco e seu olhar para o rio não será mais o mesmo.

Celeste, ao chegar a Penedo e saber que Henrique havia viajado, quer navegar rio adentro para encontrar o fotógrafo. É pela voz de Abel que tomamos 
conhecimento de outras crenças do lugar, quando ele se recusa a levá-la porque é dia santo, quando não se navega. A moça da cidade encontra-se com os repentistas, com as festas religiosas, com as carrancas do São Francisco, e ainda com um enterro, no qual as pessoas acompanham, cantam, choram e surram o defunto, para que ele se desapegue das coisas terrenas, antes de enterrá-lo. Com Abel, Celeste conhece a história dos fiéis que dormem na igreja junto com a santa, depois de dançarem e festejarem o dia todo. Bom motivo para descobrirmos que em Curaçá, próximo de Juazeiro (BA), muitos sertanejos participam da chamada Rodas de São Gonçalo, em que, depois de dançarem em agradecimento ao santo, no final comem um bode ou

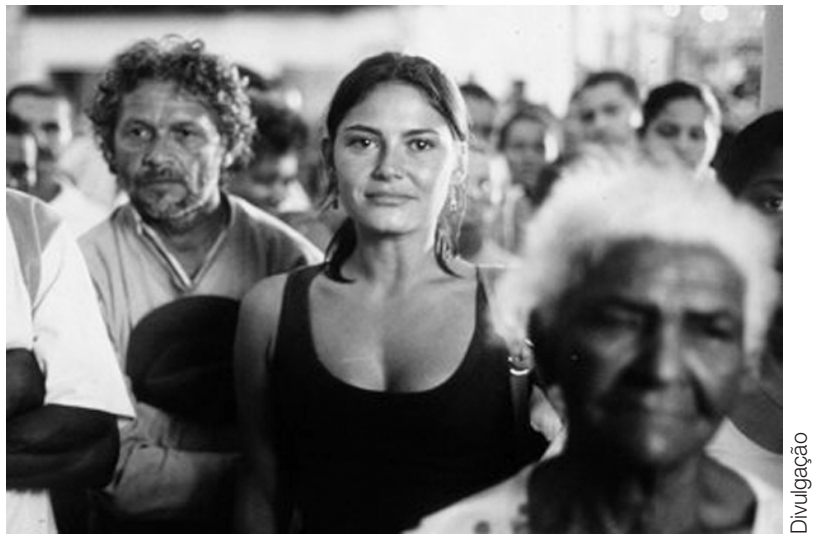

Na busca de uma pessoa, o encontro de muito mais que o esperado: histórias, lendas, milagres, superstições e crendices. uma buchada que os alimen-

ta. Vêm de todos os lugares, e muitos de longe, só para poder comer.

Não são mostradas todas as manifestações culturais do vale do São Francisco, nem é esse o propósito do diretor; por isso, o filme foi pensado como pretexto para conhecermos o que está dado a conhecer. Por exemplo, na região de Sergipe, especificamente em Curralinhos, o Auto da Cavalhada, onde a cultura nordestina também tem os reisados, os sambas de coco, as cantorias, as zabumbas e o Toré dos índios Xocó. Ou em Poço Redondo, em que é realizado o samba de coco pela comunidade quilombola de Mocambo, à margem do São Francisco. É um bom motivo para estudarmos a diversidade étnica que vive ao longo do rio-mar.

São muitas as possíveis viagens pelo vale do São Francisco. A história de Henrique tem um final feliz, bem como para os ribeirinhos do filme. Os créditos finais são apresentados em forma de xilogravura e cordel, outra parte da cultura-tradição dos nordestinos. E, nesse momento, acredito que outras pesquisas e discussões possam ser feitas. Uma delas relativa à música de Naná Vasconcelos, compositor da belíssima trilha sonora do filme, ou ao poema O Ciúme, de Caetano Veloso, que abriu este texto, ou ainda sobre todos os repentistas e poetas anônimos que cantam nos cordéis as histórias políticas, o cotidiano, as crenças e as festas que são partes inerentes da sociabilidade dos povos ribeirinhos.

Como o filme Espelho D’Água foi pensado como pretexto para estudarmos a geopolítica e a cultura do Brasil ribeirinho, e o texto iniciou-se com uma notícia sobre o jejum de dom Luiz em defesa do São Francisco e de sua população, penso ser interessante concluir este artigo com trechos do texto do sociólogo Luis Fernando Novoa Garzon, intitulado O Brasil no espelho d'água, tanto como sugestão de leitura na íntegra e de debate, quanto porque contra- 
ria aqueles que vêem a história do rio e de sua população como um universo à parte dos interesses econômicos e, principalmente, fora do contexto do mundo economicamente globalizado. Escreve o autor:

[...] em um contexto de interconexão de mercados e de harmonização de processos políticos decisórios em escala global, os "bens naturais" passam a ser vistos como estoques, mercados de commodities ou de futuros, a serem regulados pelos conglomerados transnacionais. A "governança" que querem é a que proporciona capacidade de administração meticulosa da expansão das fronteiras dos negócios oligopolizados. [...] Água não é um simples recurso, mas esteio de uma coletividade e de seus recursos. Espelho d'água que dá testemunho de como vivemos e de como podemos viver ${ }^{8}$.

E, quem sabe, através da pesquisa possamos entender melhor o ato aparentemente louco e descontextualizado de dom Luiz Flavio Cappio. Para isso, creio que pode ajudar a transcrição de um pequeno trecho da Carta de Acordo escrita pelo frei e dirigida ao presidente Luis Inácio Lula da Silva, em 6 de outubro de 2005:

\section{$[\ldots]$}

Considerando um gesto de grandeza de o senhor presidente dar continuidade ao diálogo na fase anterior ao início da possível execução das obras de transposição de águas do rio São Francisco;

Considerando o empenho do governo no projeto de revitalização [...];

Considerando que através desse amplo debate cheguemos a soluções que promovam a união e a concórdia para o povo brasileiro, especialmente para os irmãos do semi-árido, declaro:

Fica suspenso meu jejum em favor da vida [...].

Cabrobó, 6 de outubro de $2005^{9}$.

A luta contra o europeu pela posse da terra indígena foi a causa das lágrimas derramadas por Irati e da conseqüente formação do Opará. Hoje, a luta dos ribeirinhos é pelas lágrimas de Irati que formaram o São Francisco, o qual é espelho refletido de uma luta tão cruel quanto aquela.

8. Disponível em: <http:// www.correiocidadania. com.br/ed479/garzon. $\mathrm{htm}>$.

9. Disponível em: <http:// www.umavidapelavida. com.br/umavidapelavida/ carta_acordo.html>.
Resumo: A proposta desta Videografia é apresentar, a partir do filme Espelho D’Água, aspectos da geopolítica e cultura brasileiras, em especial das regiões cortadas pelo rio São Francisco. Tendo o filme como pretexto, o objetivo é estudar e discutir os problemas de um rio e, particularmente, sugerir o debate para um dos maiores problemas do momento: a preservação da água no planeta, em geral, e no Brasil, em particular.

Palavras-chave: rio São Francisco, cultura ribeirinha, preservação.
Abstract: This Videography presents, by using the motion picture Espelho D'Água, aspects of Brazilian geopolitics and culture, especially of the São Francisco River area. Using the picture as a pretext, the objective is to study and discuss the problems of a river and, in particular, to propose a debate on a major problem of today: the preservation of water in the planet and in Brazil, specifically.

Keywords: São Francisco River, riparian culture, preservation. 